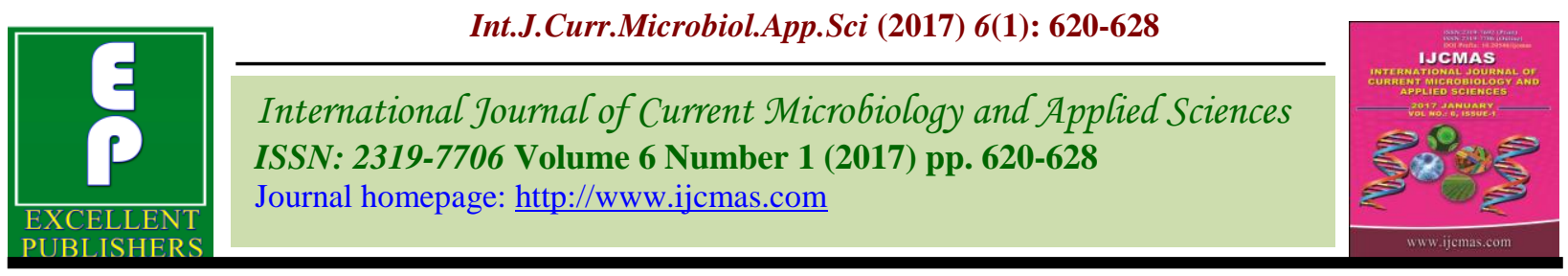

Original Research Article

http://dx.doi.org/10.20546/ijcmas.2017.601.075

\title{
Bacteriological Indoor Air Quality in Neonatal Wards of Three Tertiary Hospitals in Dar Es Salaam
}

\author{
K.D. Mwambete ${ }^{1 *}$ and G. Gaudence ${ }^{2}$ \\ ${ }^{1}$ Department of Pharmaceutical Microbiology, School of Pharmacy, Muhimbili University of \\ Health \& Allied Sciences, Dar es Salaam, Tanzania \\ ${ }^{2}$ Department of Pharmacy, Amana Regional Referral Hospital, Dar es Salaam, Tanzania \\ *Corresponding author
}

\begin{abstract}
A B S T R A C T
This study aimed to determine bacteriological quality of indoor air in neonatal wards at tertiary hospitals and assess antibiotic resistance patterns of isolated bacteria. Passive air

Keywords

Indoor air quality, antibiotic resistant isolated bacteria, neonatal wards.

Article Info

Accepted:

29 December 2016

Available Online:

10 January 2017 sampling was performed to appraise bacteriological indoor air quality employing the gravity settle plate method to monitor air quality in the morning and afternoon. Each procedure was performed in duplicate on Nutrient Agar plates for 30 and 60 minutes. A total of 75 bacteria were isolated and subjected to antibiotic sensitivity tests using the Kirby-Bauer's disk diffusion method. Staphylococcus aureus, Klebsiella pneumonia, Pseudomonas aeruginosa and Escherichia coli were the frequently isolated airborne bacteria. Staphylococcus species was predominant $(49.3 \%)$ and $6 \%$ was E. coli. The bacterial counts ranged from 19-383 cfu/plate, which was higher in the afternoon than morning. Most of the tested bacteria were sensitive to imipenem but resistant to ampicillin and ceftriaxone. Eighty percent of the bacteria were resistant to commonly used antibiotics. The fact that, the airborne bacterial counts were higher in the afternoon could be attributed to higher human influx and increased activities. Rigorous hygienic measures and observance of standard operating procedures are recommended to improve the microbiological indoor air quality and thus prevent potential infections by antibiotic resistant airborne bacteria.
\end{abstract}

\section{Introduction}

Indoor air quality refers to the air quality within and around most infrastructures, mainly as it relates to the well-being and comfort of building occupants. "There are approximately ten times as many bacterial cells in the human flora as there are human cells in the body, with large numbers of bacteria on the skin and as gut flora" (Sears, 2005). Mycobacterium tuberculosis, Streptococcus pneumoniae and Staphylococcus aureus are among the most abundant bacteria in indoor air and dust that are shed from humans (Cho and Blaser, 2012). The health care facility associated infections (HFAI)-causing bacteria can be the patient's own normal flora or originating from hospital wards' materials such as bed sheets, staff clothes, visitors as well as well-wishing cards and flowers. Files kept close to bedside in surgical wards have also been implicated as viable sources (Beggs et al., 2015; Dancer, 2009). Therefore, sources of HFAI in neonatal wards could be hospital airborne pathogens or cross-contamination from 
visitors and/or health care personnel. Hence, exposure to airborne pathogenic bacteria is a common denominator of all human life (Martin and Martin-Granel, 2006).

Evidences show that microorganisms from an infectious source may disperse over very great distances by air currents and ultimately be ingested, inhaled, or come into contact with individuals who have had no contact with the infectious source (Best and Redway, 2015; Adams et al., 2013; Polymenakou, 2012). Therefore, airborne pathogens present a major challenge in infectious diseases and infections control, as a small proportion of infectious individuals may disseminate the majority of infectious particles (Polymenakou, 2012). Numerous airborne microorganisms in healthcare settings are increasingly found to have developed multiple antimicrobial resistance (Sahoo et al., 2010; Zhou and Wang, 2013; Lax and Gilbert, 2015). The number and diversity of health care facility acquired infections (HFAI) are increasing and ubiquitous affecting both developed and resource-limited countries. In the healthcare facilities, airborne infectious particles can have varied compositions; they can be aggregates of several bacteria, fungal spores, or viruses. They can also be biologic material carried by other non-biologic particles (Sandle et al., 2014).

Although all microbial infections affecting newborns in hospitals can be considered as HFAI; infections that become evident early during the first week of life are normally due to mother-to-child transmission. Such infections present a characteristic epidemiology, different from that of hospital infections acquired later in the neonatal period. The Center for Disease Control and Prevention (CDC) considers that HFAI include those acquired intrapartum during hospitalization, or within 48 hours after hospital discharge (Yokoe et al., 2014). The exception includes transplacental infections such as syphilis, toxoplasmosis and some viral infections like herpes simplex, rubella and HIV infection just to name a few (Hawker et al., 2012; Vergnano and Heath, 2013). HFAI are among the major health problems in neonatal wards in which environmental and host factors predispose the newborns to microbial infections such as neonatal sepsis. Moreover, hospital settings are very conducive for proliferation of antimicrobial resistant and virulent pathogens. Several studies indicate an association between presence of these pathogens in the hospital air and HFAI (Lax and Gilbert, 2015; Best, 2015).

Heavily microorganisms-loaded air in hospital wards could significantly contribute to cross-contamination and infection to the occupants. Although no established guidelines are available regarding the acceptable limits; there are some recommendations on bio-burden (microbial loads) for hospital environments such that for air-conditioned areas, it is less than 18 colony forming unit per meter square $\left(\mathrm{cfu} / \mathrm{m}^{3}\right)$ for passive air sampling through gravitational settle plate with an exposure period of 15 minutes, or less than $500 \mathrm{cfu} / \mathrm{m}^{3}$ (Knoppel, 2013; WHO, 2010). Therefore, this study intended to assess the indoor air quality in neonatal wards and ascertain their antibiotics sensitivity profiles.

\section{Materials and Methods}

Study area: The study was conducted in neonatal wards of three tertiary hospitals located within Dar es Salaam City namely Muhimbili National Hospital, Temeke and Amana municipal hospitals, which for commercial and ethical purposes were arbitrary assigned letters A, B and C. The study was carried out between March and July in 2016. Permission to conduct the study was sought from both Muhimbili University 
of Health and Allied Sciences and the hospital authorities.

Samples collection and processing: Sterile 9-cm diameter Nutrient agar (NA) plates were strategically positioned in each of the surveyed neonatal wards in morning and afternoon; this was performed on two days of the week selected at random. The NA plates were exposed for 30 and 60 minutes to allow the microorganisms to settle by gravitational force. Each test was done in duplicate. Then the NA plates were transported to Pharmaceutical Microbiological Laboratory for further microbiological processing. Results of gravity settle plate sampling were expressed as numbers of viable bacteria per unit area (plate) such that colony forming unit per plate (cfu/plate). The isolated bacteria were subjected to biochemical and physiological tests for identification as per standard procedures (Cheesbrough, 2006).

\section{Antibiotic resistance profiling of bacteria}

Antibiotic sensitivity tests on the identified bacteria were performed on Muller Hinton agar plates (Difco, Becton, Dickinson and Company, Sparks, MD) using the KirbyBauer's disk diffusion method and interpreted as per the Clinical \& Laboratory Standards Institute (CLSI) guidelines (CLSI, 2011). The following 10 most commonly used antibiotics were employed in the tests: ampicillin $10 \mu \mathrm{g}$, amoxicillin-clavulanic acid $30 \mu \mathrm{g}$, cotrimoxazole 25 $\mathrm{g}$ (Oxoid, England), chloramphenicol $30 \mu \mathrm{g}$, vancomycin $30 \mu \mathrm{g}$ and

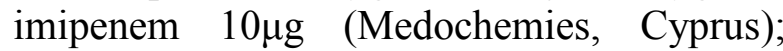
others were ceftriaxone $30 \mu \mathrm{g}$, amikacin $30 \mu \mathrm{g}$, piperacillin $100 \mu \mathrm{g}$ and ceftazidime $30 \mu \mathrm{g}$ (Pharmathen-SA, Greece). Quality control testing was performed using the following organisms: Escherichia coli ATCC (American Type Culture Collection) 25922, Staphylococcus aureus (ATCC 25923),
Klebsiella pneumoniae (ATCC 700603) and Pseudomonas aeruginosa (ATCC27853).

\section{Statistical Data Analysis}

Each air sampling procedure was conducted in duplicate and performed twice (morning and afternoon) for statistical purpose and consistence of results. Hence, resultant numerical data are expressed as mean. Statistical data analysis (means and variance) for zones of inhibition (IZ) and correlation between bacterial counts (cfu/plate) and NA plate exposure time were carried out using the computer package SPSS version 20 (Chicago, IL). Differences of means for ZI among the bacteria were compared to that of reference strains of bacteria and analyzed by the T-test; and the differences were considered statistically significant when $\mathrm{p}<0.05$.

\section{Results and Discussion}

\section{Quantification of airborne bacteria}

A total of 75 airborne bacteria from neonatal wards were isolated and identified. Of these, slightly less than half $(49.3 \%$; $=37)$ were Staphylococcus species, of which $S$. aureus constituted $89.2 \% \quad(\mathrm{n}=33)$. Escherichia coli were the least frequently isolated enteric bacteria (Table 1).

Likewise, there were significant differences with regard to total viable counts of airborne bacteria in the wards between evening and morning among the surveyed wards in the three hospitals $(p<0.05)$. The number of different isolated bacteria was relatively higher in the morning (Table 1); however, the viable bacterial counts were higher in the afternoon (Figure 1). Though, the difference of a number of airborne bacteria sampled in the morning and evening was statistically not significant $(\mathrm{p}>0.05)$. 
Table.1 A number of bacteria isolated from indoor air in neonatal wards (in the morning and afternoon)

\begin{tabular}{|c|c|c|c|c|c|c|c|}
\hline \multirow{2}{*}{$\begin{array}{l}\text { Sampling } \\
\text { period }\end{array}$} & \multirow[t]{2}{*}{ Hospita } & \multicolumn{5}{|c|}{ Number of isolated of bacteria $(\%)$} & \multirow[t]{2}{*}{ Total } \\
\hline & & S. aureus & P. aeruginosa & K. pneumonia & E. coli & S. epidermidis & \\
\hline \multirow[t]{3}{*}{ Morning } & $\mathrm{A}$ & $7(38.9)$ & $3(49.3)$ & $2(25.0)$ & $1(25.0)$ & $2(66.7)$ & $15(38.4)$ \\
\hline & $\mathrm{B}$ & $5(27.8)$ & $2(34.2)$ & $2(25.0)$ & $2(50.0)$ & $1(33.3)$ & $12(30.9)$ \\
\hline & $\mathrm{C}$ & $6(33.3)$ & $1(16.4)$ & $4(50.0)$ & $1(25.0)$ & $0(0.0)$ & $12(30.7)$ \\
\hline Total & & $18(100.0)$ & $6(100.0)$ & $8(100.0)$ & $4(100.0)$ & $3(100.0)$ & $39(100.0)$ \\
\hline \multirow[t]{3}{*}{ Afternoon } & A & $5(33.3)$ & $4(40.3)$ & $2(33.3)$ & $2(50.0)$ & $0(0.0)$ & $13(36.2)$ \\
\hline & B & $6(40.0)$ & $2(19.3)$ & $3(50.0)$ & $1(25.0)$ & $0(0.0)$ & $12(33.2)$ \\
\hline & $\mathrm{C}$ & $4(26.7)$ & $4(40.3)$ & 1(16.7) & $1(25.0)$ & $1(100.0)$ & 11(30.6) \\
\hline Total & & $15(100.0)$ & $10(100.0)$ & $6(100.0)$ & $4(100.0)$ & $1(100.0)$ & $36(100.0)$ \\
\hline
\end{tabular}

Table.2 Antibiotic sensitivity patterns displayed by isolated bacteria

\begin{tabular}{lrcc}
\hline Microbes & \multicolumn{3}{c}{ Remark } \\
\cline { 2 - 4 } & Susceptible & Intermediate & Resistant \\
\hline STA $(\mathrm{n}=33)$ & $23(70.0)$ & $3(9.0)$ & $7(21.0)$ \\
PSE $(\mathrm{n}=16)$ & $9(58.0)$ & $6(34.0)$ & $1(7.0)$ \\
KLE $(\mathrm{n}=14)$ & $9(65.0)$ & $3(21.0)$ & $2(13.0)$ \\
ECO $(\mathrm{n}=8)$ & $7(78.0)$ & $1(13.0)$ & $0(0.0)$ \\
STE $(\mathrm{n}=4)$ & $3(75.0)$ & $0(0.0)$ & $1(25.0)$ \\
Total $(\mathbf{n}=\mathbf{7 5})$ & $\mathbf{5 2}(\mathbf{6 9 . 3})$ & $\mathbf{1 2}(\mathbf{1 6 . 0})$ & $\mathbf{1 1}(\mathbf{1 4 . 7})$ \\
\hline
\end{tabular}

Fig.1 Airborne bacterial counts in neonatal wards in the morning and afternoon

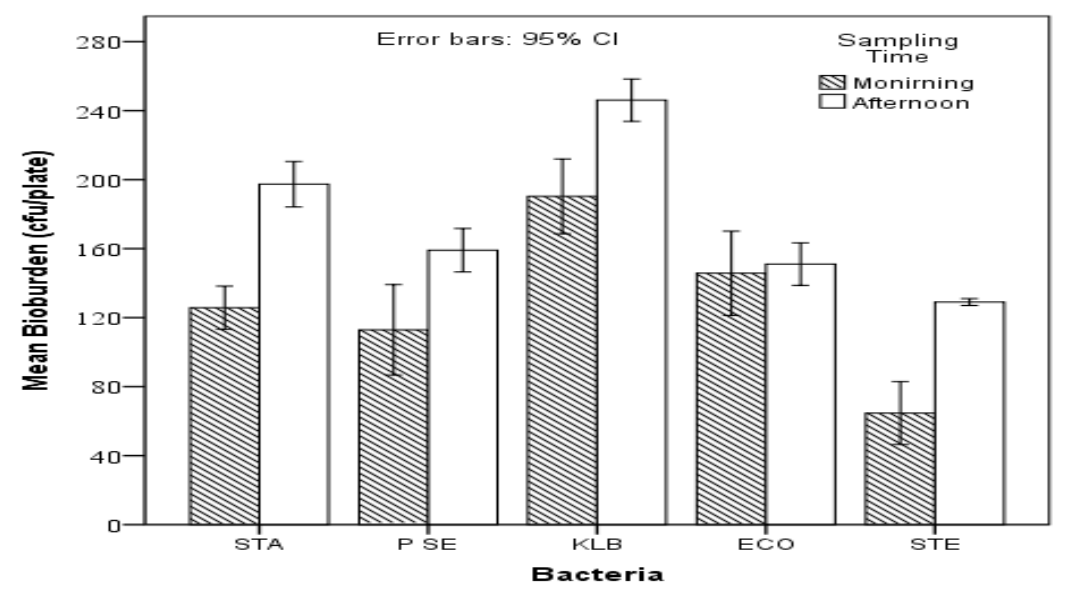


Fig.2 Indoor airborne bacterial counts among the hospital wards.

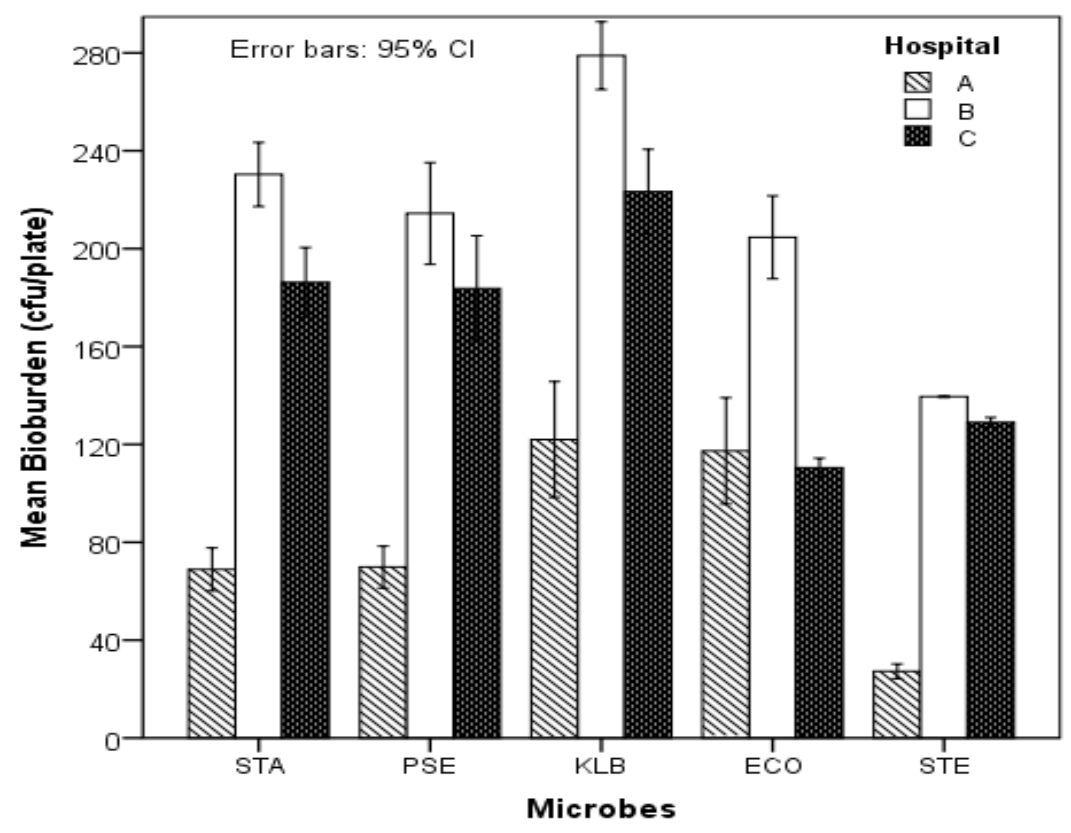

Fig.3 Variation of airborne bacteria quantity by exposure time (30 v 60 minutes).

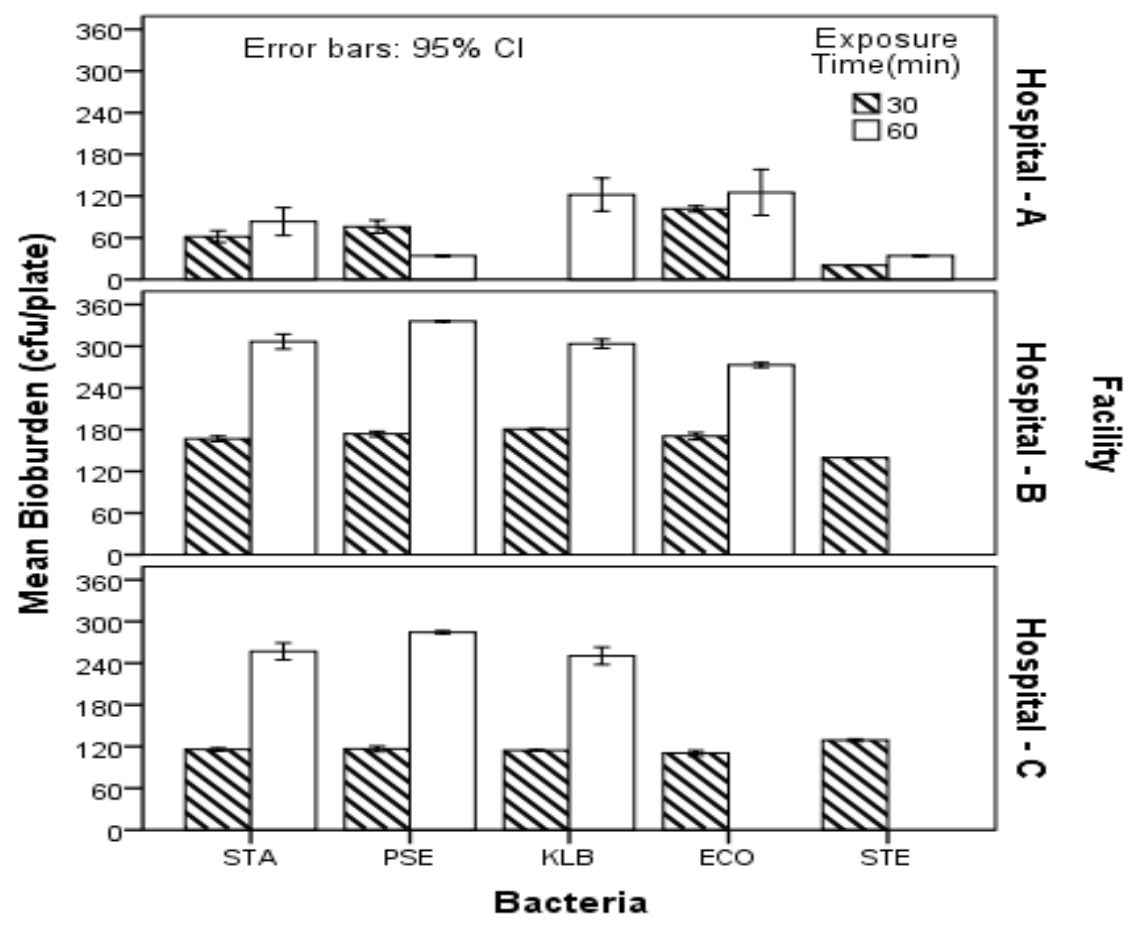

A relatively higher quantity (cfu/plate) of indoor airborne Klebsiella pneumonia and $S$. aureus were encountered in the afternoon as compared to morning hours, while the least were S. epidermidis. The aerobic counts of airborne bacteria ranged from 19-383 
cfu/plate (with mean of 50-270cfu/plate) as shown in Figure 1. Hospital B revealed the highest bacterial counts, ranging from 150$300 \mathrm{cfu} /$ plate (Figure 2). About $80 \%$ of the sampled NA plates revealed high bacterial counts from the indoor air in the wards (data not included).

A positive correlation $(\mathrm{R}=0.493 ; \mathrm{p}<0.001,2$ tailed) between exposure time of NA plates and bacterial counts was evident in all wards/hospitals. Association between exposure time of NA plates (for 30 and 60 minutes) and bacterial counts was also observed $(p<0.001)$. Similarly, significant differences of indoor bacterial counts obtained at 30 and 60 minutes were apparent $(\mathrm{p}=0.01)$ as shown in Figure 3. Regression analysis also showed that a unit increase in exposure time of the NA plates led to increase of bacterial counts by $0.493(\mathrm{p}<0.001)$.

\section{Antibiotic resistance profiling of airborne bacteria from the neonatal wards}

A total of $11(14.7 \%)$ and $12(69.3 \%)$ isolated bacteria exhibited resistance and susceptibility to the tested antibiotics. About $54.5 \%(\mathrm{n}=18)$ S. aureus isolates were resistant to the antibiotics (Table 2). No statistical significant differences were observed with regard to prevalence rates of antibiotic resistance among isolated bacteria in the surveyed hospital wards ( $\mathrm{p}>0.05$ ).

The bacteria exhibited resistance against 5 of 10 tested antibiotics namely amoxicillinclavulanic acid, vacomycin, chlorampenicol, ampicillin and ceftazidime. About $81 \%$ $(n=39)$ of the samples (NA plates) exceeded the airborne bacterial counts/quantity limits; of those $14.2 \% \quad(n=7)$ yielded resistant bacteria to the tested antibiotics. About 21\% $(\mathrm{n}=7)$ of $S$. aureus were resistant to ampicillin. An overall rate of antibiotic resistance observed among the tested bacteria was $80 \%$. Moreover, only $67 \%$ of the tested bacteria were sensitive to imipenam.

The presence of airborne bacteria in hospital environments is of great concern because of their potential role as a source of HFAI. Hospital indoor air may contain a wide range of pathogenic and non-pathogenic microorganisms which could originate from patients, staff, visitors, ventilation and air conditioning systems (Sandle et al., 2014). Although some airborne bacteria in the hospital settings may be harmless to healthy people, they can impact negatively on a vulnerable group of hospitalized patients and cause serious threats to health (Mirhoseini et al., 2015). Newborns in neonatal wards are at great risk of HFAI due to drastic environmental changes from sterile uterus to non-sterile neonatal unit. Because of their immature immune systems, they become prone to infectious microbial diseases, including from airborne pathogens (Kan et al., 2016; Sullivan and Goodier, 2015).

The present study indicates that the indoor airborne bacterial counts in the surveyed wards were relatively higher than the acceptable limits (WHO, 2010; Knopel, 2013). The indoor air quality was relatively poor in the afternoon than morning. Among various factors that may attribute to this observation, include an increased influx of patients' relatives and medical personnel into the ward as result of increased activities in the wards. Not only that patients, visitors and health care personnel harbor normal flora on their bodies that are carried to the wards, but also foodstuffs and other materials usually brought to the wards contribute to the increased microbial loads. Hence more microorganisms could have been discharged into the air (Qudiesat, et al 2009). Such influx of airborne bacteria could increase airborne transmitted HFAI (Kowalski et al., 2013). Some of the airborne bacteria recovered from the neonatal wards include potentially pathogenic bacteria such $E$. coli and $P$. 
aeruginosa and other opportunistic bacteria such as S. aureus and K. pneumonia. Presence of $S$. aureus in the indoor environment or in the hospital settings may be because of its minimal growth requirements, high resistance to harsh conditions and its easy transmission through agents such as throat, skin, and nails. In addition to that the bacterium can colonize and establish infection in most parts of human body and (Cho and Blaser, 2012; Zhou and Wang, 2013).

Among the isolated bacteria namely $S$. aureus, Klebsiella spp and E. coli have been attributed to HFAI such as neonatal septicemia, meningitis, pneumonia and urinary tract infections. Such infections constitute a major concern for public health because of the increased length of stay of patients and the cost of hospital care they may cause (Sullivan and Goodier, 2015). To a large extent, this can be ascribed to antibiotic resistance, which is not uncommon in such health facilities. Our findings showed that most of the isolated bacteria were resistant to commonly prescribed antibiotics namely ampicillin, amoxyclav, cotrimoxazole, chloramphenicol, vancomycin and aminoglycosides (gentamicin and amikacin). Gram positive bacteria, particularly Staphylococcus spp exhibited resistance to ampicillin, which is a broad spectrum beta lactam; and a drug of choice for such bacteria (Tang et al., 2014). Among other factors, this could due to clonal outbreak of betalactamase producers in hospital settings.

Staphylococcus aureus is a major human pathogen that causes a wide range of diseases. Apart from causing external lesions and systemic infections, the bacterium is also responsible for toxin-mediated diseases, such as toxic shock syndrome and staphylococcal food poisoning (Johler et al., 2015; Resch et al., 2008). Staphylococcus epidermidis is one of the important causes of HFAI, largely because its ability to form/ accumulate intracellular calcium-dependent andindependent biofilm on the surfaces of indwelling medical devices (Khan, et al., 2015; Cheung and Otto, 2010). On the other hand, $P$. auruginosa exerted the highest rates of antibiotic resistance to amoxicillinclavulanic acid and ceftriaxone; these are antibiotics ( $\beta$-lactamase inhibitors) intended for beta-lactamase producing bacteria and a third generation broad spectrum cephalosporin respectively. Both antibiotics are second line drugs in case of resistance to first line beta-lactams (Zhanel et al., 2014; Tang et al., 2014). Ever since, these antibiotics have been useful in treating HFAI, although increasing levels of extendedspectrum beta-lactamases are reducing the clinical utility of this class of antibiotics.

In conclusion, Staphylococci were the most frequently isolated airborne bacteria in neonatal wards and hence they are potential air contaminants. Isolation of high bacterial counts of both normal flora and coliform bacteria is of health concern. High rates of antibiotic resistance were observed among the isolated bacteria, particularly against commonly used antibiotics such as ampicillin, amoxicillin-clavulanic acid and ceftriaxone. Relatively higher bacterial counts were apparent in the afternoon as compared to morning, which could be attributed not only to higher human influx of patient relatives, health care workers and increased human activities in the afternoon, but also poor sanitation and environmental contaminations.

More stringent hygienic measures should be imposed to improve the indoor air quality in the neonatal wards and prevent spread of antimicrobial resistance by the contaminant bacteria. Standard operating procedures on infection control should be strictly adopted at all the levels of health care delivery. Finally, we suggest that further studies should be 
conducted in order to ascertain association between bacterial counts of airborne bacteria with incidences of HFAI in hospital settings in Dar es Salaam

\section{Acknowledgement}

Authors wish to acknowledge the financial support from the Ministry of Education and Vocational Training-Tanzania for making this study possible. They also appreciate for cooperation offered by all study participants, MUHAS and the respective hospital authorities.

\section{References}

Adams, R.I., Miletto, M., Taylor, J.W., Bruns, T.D. 2013. Dispersal in microbes: fungi in indoor air are dominated by outdoor air and show dispersal limitation at short distances. The ISME J., 7(7):1262-73.

Beggs, C., Knibbs, L.D., Johnson, G.R. and Morawska, L., 2015. Environmental contamination and hospital-acquired infection: factors that are easily overlooked. Indoor Air, 25(5): 462-474.

Best, E.L. and Redway, K. 2015. Comparison of different hand-drying methods: the potential for airborne microbe dispersal and contamination. J. Hosp. Infect., 89(3):215-7.

Cheesbrough, M. 2006. District Laboratory Practice in Tropical Countries.Part 2, Second Edition. Cambridge University Press, The Edinburgh Building, Cambridge, CB2 8RU, UK.

Cheung, G.Y. and Otto, M., 2010. Understanding the significance of Staphylococcus epidermidis bacteremia in babies and children. Curr. Opin. Infect. Dis., 23(3): 208.

Cho, I. and Blaser, M.J. 2012. "The human microbiome: at the interface of health and disease." Nat. Rev. Genet, 13(4): 260-270.

CLSI-Clinical and Laboratory Standards Institute (CLSI) guidelines. 2011. Performance Standards for Antimicrobial Susceptibility Testing; 21st Informational Supplement.
Update M100-S21. Wayne, PA: Clinical and Laboratory Standards Institute.

Dancer, S.J., 2009. The role of environmental cleaning in the control of hospital-acquired infection. J. Hosp. Infect, 73(4): 378-385.

Hawker, J., Begg, N., Blair, I., Reintjes, R., Weinberg, J. and Ekdahl, K., 2012. Communicable disease control and health protection handbook. John Wiley \& Sons.

Johler, S., Weder, D., Bridy, C., Huguenin, M.C., Robert, L., Hummerjohann, J. and Stephan, R., 2015. Outbreak of staphylococcal food poisoning among children and staff at a Swiss boarding school due to soft cheese made from raw milk. $J$. Dairy Sci., 98(5):2944-2948.

Kan, B., Razzaghian, H.R. and Lavoie, P.M., 2016. An Immunological Perspective on Neonatal Sepsis. Trends Mol. Med., 22(4): 290-302.

Khan, B.A., Yeh, A.J., Cheung, G.Y. and Otto, M., 2015. Investigational therapies targeting quorum-sensingfor the treatment of Staphylococcus aureus infections. Expert OpinInvestig Drugs, 24(5): 689-704.

Knöppel, H. and Wolkoff, P. 2013. Chemical, Microbiological, Health and Comfort Aspects of Indoor Air Quality-State of the Art in SBS (Vol. 4). Springer Science \& Business Media.

Kowalski, R.P. 2013. "Is antibiotic resistance a problem in the treatment of ophthalmic infections?" Expert Rev. Ophthalmol., 8(2): 119-126.

Lax, S., and Gilbert, J.A. 2015. Hospitalassociated microbiota and implications for nosocomial infections. Trends Mol. Med., 31;21(7):427-32.

Martin, P.M.V. and Martin-Granel E. 2006."2,500-year evolution of the term epidemic," Emerg. Infect. Dis., 12(6): 976980.

Mirhoseini, S.H., Nikaeen, M., Khanahmad, H., Hatamzadeh, M., Hassanzadeh, A. 2015. Monitoring of airborne bacteria and aerosols in different wards of hospitals-Particle counting usefulness in investigation of 
airborne bacteria. Ann. Agric. Environ. Med., 22(4): 670-673.

Polymenakou, P.N. 2012. Atmosphere: a source of pathogenic or beneficial microbes? Atmosphere, 3(1):87-102.

Qudiesat, K., Abu-Elteen, K., Elkarmi, A., Hamad, M. and Abussaud, M., 2009. Assessment of airborne pathogens in healthcare settings. Afr. J. Microbiol. Res, 3(2):66-76.

Resch, M., Nagel, V. and Hertel, C. 2008. Antibiotic resistance of coagulase-negative staphylococci associated with food and used in starter cultures. Int. J. Food Microbiol, 127(1): 99-104.

Sahoo, K.C., Tamhankar, A., Johansson, E., Lundborg, C.S. 2010. Antibiotic use, resistance development and environmental factors: a qualitative study among healthcare professionals in Orissa, India. BMC Public Health, Oct 21; 10(1):1.

Sandle, T., Leavy, C., Rhodes, R. 2014. Assessing airborne contamination using a novel rapid microbiological method. Eur J Parenteral Pharm. Sci., 19(4):131-42.

Sears, C.L 2005. "A dynamic partnership: celebrating our gut flora". Anaerobe, 11(5): 247-51.

Sullivan, S.A. and Goodier, C., 2015. Intrapartum and postpartum infections. Management of Labor and Delivery, Second Edition, pp.376-415.

Tang, S.S., Apisarnthanarak, A. and Hsu, L.Y.,
2014. Mechanisms of $\beta$-lactam antimicrobial resistance and epidemiology of major community-and healthcareassociated multidrug-resistant bacteria. Adv. Drug Deliver Rev., 78: 3-13.

Vergnano, S. and Heath, P.T., 2013. Fetal and neonatal infections. Med., 41(12), pp.723729.

WHO-guidelines for indoor air quality selected pollutants, WHO, 2010.

Yokoe, D.S., Anderson, D.J., Berenholtz, S.M., Calfee, D.P., Dubberke, E.R., Ellingson, K.D., Gerding, D.N., Haas, J.P., Kaye, K.S., Klompas, M. and Lo, E., 2014. A compendium of strategies to prevent healthcare-associated infections in acute care hospitals: 2014 updates. American J. infection control, 42(8), pp.820-828.

Zhanel, G.G., Chung, P., Adam, H., Zelenitsky, S., Denisuik, A., Schweizer, F., Lagacé-Wiens, P.R., Rubinstein, E., Gin, A.S., Walkty, A. and Hoban, D.J. 2014 "Ceftolozane/tazobactam: A novel cephalosporin/ $\beta$-lactamase inhibitor combination with activity against multidrugresistant bacilli". Drugs, 74 (1): 31-51.

Zhou, F., and Wang, Y. 2013. Characteristics of antibiotic resistance of airborne Staphylococcus isolated from metro stations. Int. J. Environ. Res. Public Health, 10(6):2412-26.

\section{How to cite this article:}

Mwambete, K.D., and Gaudence, G. 2017. Bacteriological Indoor Air Quality in Neonatal Wards of Three Tertiary Hospitals in Dar Es Salaam. Int.J.Curr.Microbiol.App.Sci. 6(1): 620628. doi: http://dx.doi.org/10.20546/ijcmas.2017.601.075 